\title{
CORRIGENDUM
}

\section{Dysregulation of DGCR6 and DGCR6L: psychopathological outcomes in chromosome 22q11.2 deletion syndrome}

\author{
D Chakraborty, AJ Bernal, K Schoch, TD Howard, EH Ip, SR Hooper, MS Keshavan, RL Jirtle and V Shashi
}

Translational Psychiatry (2012) 2, e124; doi:10.1038/tp.2012.52; published online 29 May 2012

Correction to: Translational Psychiatry (2012) 2, e105; doi:10.1038/tp.2012.31; published online 24 April 2012
Following the online publication of this article, the authors noted an error in Dr Chakraborty's name. The complete and correct author name is R Das Chakraborty. 